\title{
Coalescence of inter: Osteotomy bone graft material inserted via separate transcrestal sinus osteotomies: A case report and concise review of the literature
}

Shane J. J. McCrea ${ }^{1}$

Correspondance: Dr. Shane J. J. McCrea, Email: shanemccrea@aol.com
'Principal, The Dental Implant and Gingival-plastic Surgery Centre, Bournemouth, Dorset, UK

\section{ABSTRACT}

When multiple implants are to be placed, and a pneumatized sinus exists, the published reports suggest that the lateral window approach (LWA) is favored for sinus floor augmentation. Simultaneously, if a transcrestal sinus floor augmentation has been carried out (bone-added osteotome sinus floor elevation), the reports are restricted to single implant placement at any site. The aim of this study was to evaluate the clinical and radiographic outcomes at adjacent transcrestal sinus augmentation grafts using deproteinized bovine bone material, with the immediate placement of submerged adjacent implants, and so determining the fate of the graft material. The progressive loss of the inter-implant graft is reported for the LWA Technique. However, this novel coalescence method has shown a progressive increase in the inter-implant graft region, thus inferring a positive bony regeneration and remodelling at the region. These results indicate that the carrying out of a large scale study is warranted to confirm the efficacy of this technique.

Key words: Dental implants, sinus graft, transcrestal, xenograft

\section{INTRODUCTION}

The loss of teeth from the posterior maxilla will certainly result in the loss of bone depth of the residual ridge; the depth decrease becoming more profound with time. ${ }^{[1,2]}$ Additionally, with time, the pneumatization of the sinus is to be expected. ${ }^{[3]}$ A profound reduction in bone volume will certainly complicate the rehabilitation of the posterior edentulous maxilla with implant-supported prostheses. However, where the residual bone height is $>5 \mathrm{~mm}$ and primary stability of an introduced dental implant has been achieved, it has been shown that the simple elevation of the sinus lining can be sufficient to regenerate new bone: The periosteum itself having sufficient osteo-regenerative capacity ${ }^{[4-6]}$ to repair, regenerate and remodel the sinus floor. Where the residual bone depth is $<5 \mathrm{~mm}$, various sinus grafting procedures have been used to increase the bone depth and volume by raising the anatomical floor of the sinus cavity at the site of a prospective dental implant osteotomy by using autogenous bone and/or a biomaterial. ${ }^{[7,8]}$

Essentially, there are three methods of raising the sinus floor, either to simply raise the sinus lining or to additionally introduce bone regenerative material under the lining: There is, (1) The lateral window approach (LWA). ${ }^{[9,10]}$ (2) The bone-added osteotome sinus floor elevation (BAOSFE). ${ }^{[11,12]}$ (3) Crestal core elevation. In addition, the sinus floor can simply be penetrated, thus, allowing full usage of all the available bone at the osteotomy site with no direct augmentation; this is the simple perforation. ${ }^{[6]}$

In the last 30 years many articles have been published describing the successful use of different augmentation materials that can be placed under the sinus lining: Aghaloo and Moy, ${ }^{[13]}$ in a systematic review, where 5128 implants were placed with a follow-up ranging from 12 to 102 months, implant survival was 92\% for implants placed into autogenous bone and

\footnotetext{
How to cite this article: McCrea SJ. Coalescence of inter: Osteotomy bone graft material inserted via separate transcrestal sinus osteotomies: A case report and concise review of the literature. Eur J Dent 2014;8:553-8.

Copyright $@ 2014$ Dental Investigations Society. DOI: $10.4103 / 1305-7456.143642$
} 
autogenous/composite grafts, $93.3 \%$ for implants placed in allogenic/nonautogenous composite grafts, $81 \%$ for implants placed in alloplast and alloplast/ xenograft materials, and $95.6 \%$ for implants placed into xenograft material alone.

Other studies havealso compared the delayed placement of dental implants into the sinus graft against immediate placement. In a systematic review ${ }^{[14]}$ of implant survival rates in the grafted sinus that took into account the influence of implant surface, graft material and implant placement timing, it was found that simultaneous and delayed procedures had similar outcomes.

Thus, with the success of the various surgical techniques, the sinus grafting materials and the simultaneous placement of the implants, Hatano et al. ${ }^{[15]}$ went on to assess the long term changes in sinus-graft height after maxillary sinus floor augmentation (LWA) and simultaneous placement of implants: A total of 191 patients undergoing sinus floor augmentation with 2:1 mixture of autogenous bone/xenograft (Bio-Oss) were radiographically followed-up for up to 10 years. Changes in sinus-graft height were calculated with respect to implant length and original sinus floor depth. After augmentation, the grafted sinus floor was always located above the implant apex. After 2-3 years, the grafted sinus floor was level with or slightly below the implant apex. This relationship was maintained over the long term. The results showed that the sinus-graft height decreased significantly and approached the original sinus height. The number of patients having the sinus floor below the implant apex reached a maximum after 3 years. The clinical survival rate was $94 \%$, with implant losses occurring within 3 years of augmentation. They concluded that progressive sinus pneumatisation occurs after augmentation with 2:1 autogenous bone/ xenograft mixture and the long term stability of the sinus-graft height influences implant success.

More recently, Trombelli et al. ${ }^{[16]}$ in a randomized study of 30 sites in 30 patients compared the use of deproteinized bovine bone mineral, deproteinized bovine bone material (DBBM) $(n=15)$ and synthetic hydroxyapatite (S-HA) in a collagen matrix, S-HA $(n=15)$ as grafting materials when using the transcrestal sinus floor elevation. The extent of the sinus lift and the height of the graft above the implant apex were assessed on periapical radiographs taken immediately after surgery and at 6 months following surgery. The results showed that both materials resulted in a substantial increase in sinus floor depth and produced a substantial height of graft maintained graft material above the implant apex at 6 months postsurgery. However, the measurements obtained with the S-HA were superior to those with DBBM. Limited complications and postoperative pain/discomfort were recorded for both materials.

When multiple implants are to be placed, and a pneumatised sinus exists, the published reports suggest that an LWA is favoured for sinus floor augmentation. At the same time, if a transcrestal sinus floor augmentation has been carried out (the BAOSFE), the reports are restricted to single implant placement at any site. The aim of this preliminary study was to evaluate the clinical and radiographic outcome of adjacent transcrestal sinus augmentation grafts using DBBM, DBBM ${ }^{1}$, with the immediate placement of submerged adjacent implants, ${ }^{2}$ and thus determine the fate of the graft material.

\section{CASE REPORT}

A male Caucasion, 62 years of age presenting at a private practice devoted to implant and periodontal therapy, and advanced restorative treatment. Teeth 16 and 15 (Federation Dentaire Internationale-notation) were missing, having been extracted 8 months previously [Figure 1]. The patient requested that the teeth be replaced with dental implants. A periapical radiograph [Figure 2], with "ball-bearing" in place ( $5 \mathrm{~mm}$ in diameter) showed that there was $<5 \mathrm{~mm}$ of residual bone depth available for implant placement. The BAOSFE "summers technique" was explained to the patient. The patient signed informed consent before treatment.

\section{Bio-Oss, Geistlich, Wolhusen, Switzerland. 2 MIS, Tel Aviv, Israel.}

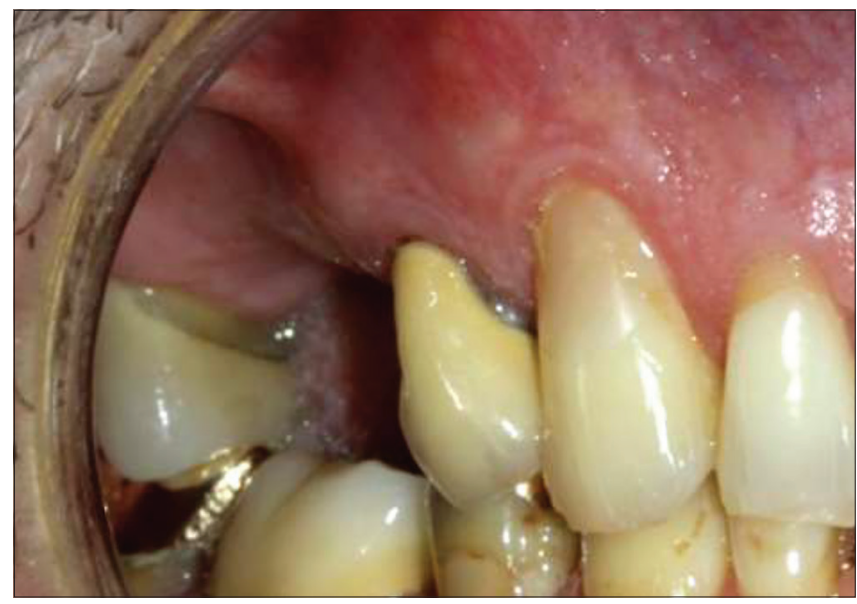

Figure 1: Pretreatment clinical situation 


\section{MATERIALS AND METHODS}

Preextraction: $1 \mathrm{~h}$ prior to surgery the patient received systemic coverage $-2 \mathrm{~g}$. Amoxicillin, $400 \mathrm{mg}$ ibuprofen, $2 \mathrm{mg}$ dexamethasone. In addition, mouthrinse of chlorhexidine gluconate $2 \%, 20 \mathrm{~min}$ prior to surgery.

Under intravenous sedation and local anaesthesia, at the chosen implant sites, a crestal incision was made over the proposed transalveolar osteotomy sites, that is, at the inferior border of the maxillary sinus. Minimal mucoperiosteal flaps were raised to allow objective scrutiny of the two sites. The two osteotomies were prepared with palatal displacement of their axis ${ }^{[17,18]}$ and taken to the accessed depthapproximately $1-2$ mm coronal from the sinus floor. An accompanying trans-socket sinus penetration/lift facilitated with osteotomes ${ }^{3}$ was then carried out at each separate site. Following this minimal penetration/fracture, the sinus lining was checked circumferentially for integrity with a specified socket probe. ${ }^{4}$ The procedure elevated the sinus (Schneiderian) membrane, creating a classical "tent." In this way, space was provided for bone graft placement or blood clot formation. Particulate xenograft, $0.25-1 \mathrm{~mm},{ }^{5}$ mixed with sterile water was introduced incrementally into each osteotomy. The condensation pressure from the osteotomes, graft material and the trapped fluids exerted hydraulic pressure on the sinus membrane causing it to elevate. ${ }^{[10]}$ Engelke and Deckwer ${ }^{[19]}$ have shown in an endoscopic study that the membrane can be elevated by $5 \mathrm{~mm}$ without perforation. The volume and hydrostatic

\begin{tabular}{ll}
\hline 3 & Tatum Instruments, Clearwater, Fl, USA. \\
4 & MIS, Tel Aviv, Israel \\
5 & Bio-Oss, Geistlich Pharma, Wohlhusen, \\
& Switzerland
\end{tabular}

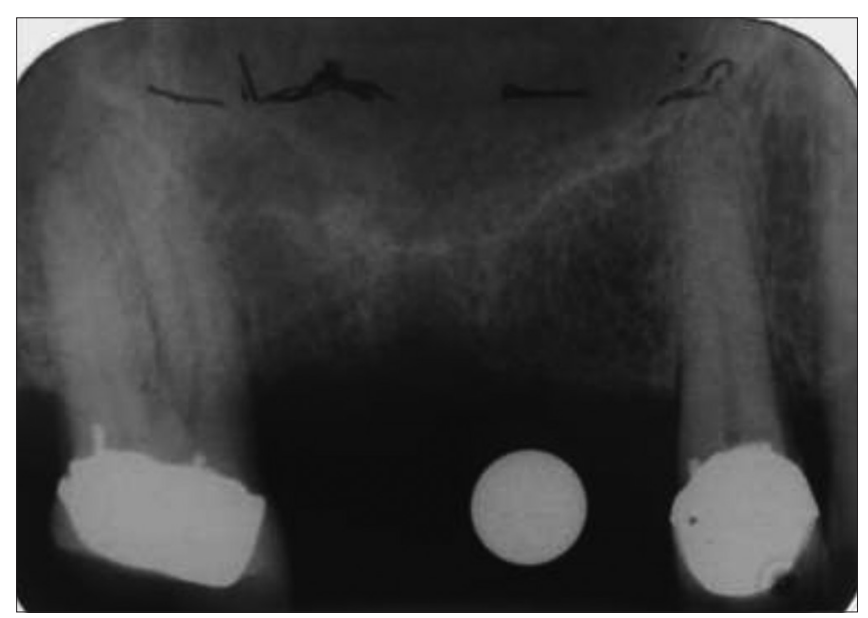

Figure 2: Pretreatment periapical radiograph pressure from each osteotomy site caused the eventual coalescence of the two osteotomies. Dental implants ${ }^{6}$ were immediately placed into the osteotomies [Figure 3]: Both implants were sandblasted and acid-etched -surface titanium, self-tapping screws. Both implants were inserted mechanically with an initial seating torque $=50 \mathrm{Ncm}$, determined by precalibration of the implant drive unit, ${ }^{7}$ final seating was with a hand wrench in excess of $50 \mathrm{Ncm}$. Cover screws were fitted and the wound site closed with 4.0 vicryl resorbable sutures. ${ }^{8}$ Postoperative medication was $2 \mathrm{mg}$ dexamethasone once daily for 3 days and $400 \mathrm{mg}$ ibuprofen 4 times daily for 3 days. The patient was reviewed at 1, 3, 6 and 12 weeks postoperatively. No postoperative pain, swelling or complications were recorded at any of the visits.

At 6 months postsurgery, the implants were uncovered via a simple crestal incision displaced to the palatal aspect and the buccal mucoperiosteal tissue displaced to the buccal aspect, the Abrams roll. $4 \mathrm{~mm}$ high gingival formers (healing caps) were fitted to each implant with a seating torque of $20 \mathrm{Ncm}$.

At 3 weeks postuncovering, impressions were taken of the implants. Two weeks later, crowns were fitted to the implants. Using a standardized Rinn film-holder ${ }^{9}$ in the long-cone parallel technique, periapical radiographs were taken at crown fit, and at 6 and 12 months postcrown fit [Figures 4-6 and 9].

\begin{tabular}{ll}
\hline 6 & MIS, Tel Aviv, Israel. \\
7 & Implantmed, W and H International, St \\
& Albans, UK. \\
8 & Johnson and Johnson, New Jersey, USA. \\
9 & Rinn, Dentsply, Elgin, IL, USA.
\end{tabular}

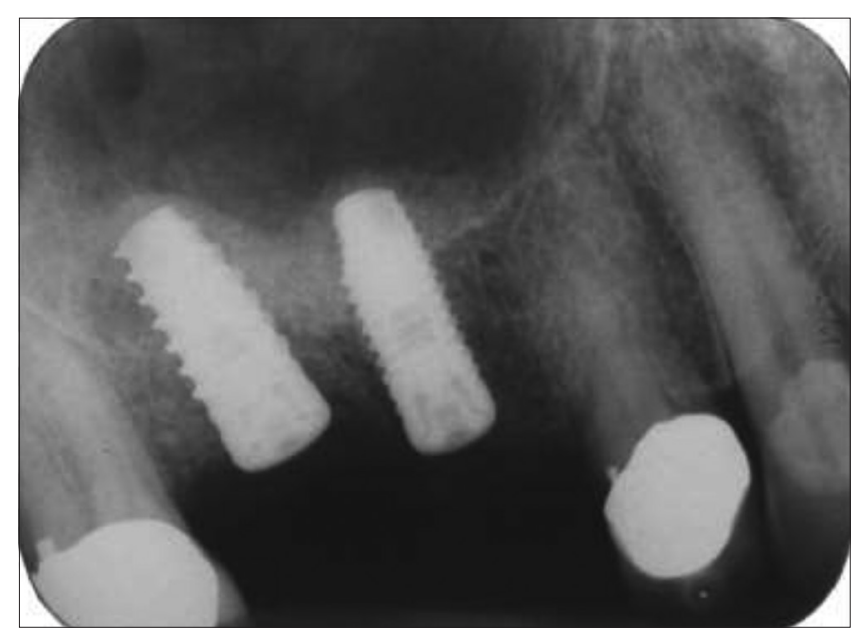

Figure 3: Periapical radiograph taken immediately following the adjacent transcrestal (osteotomies) sinus grafts (using deproteinised bovine bone material) and the immediate placement of the implants 


\section{Analysis of radiographs}

All radiographs were photographed and digitized. Using Adobe Photoshop elements nine (Adobe Systems Incorp., San Jose, CA, USA) and methodology already

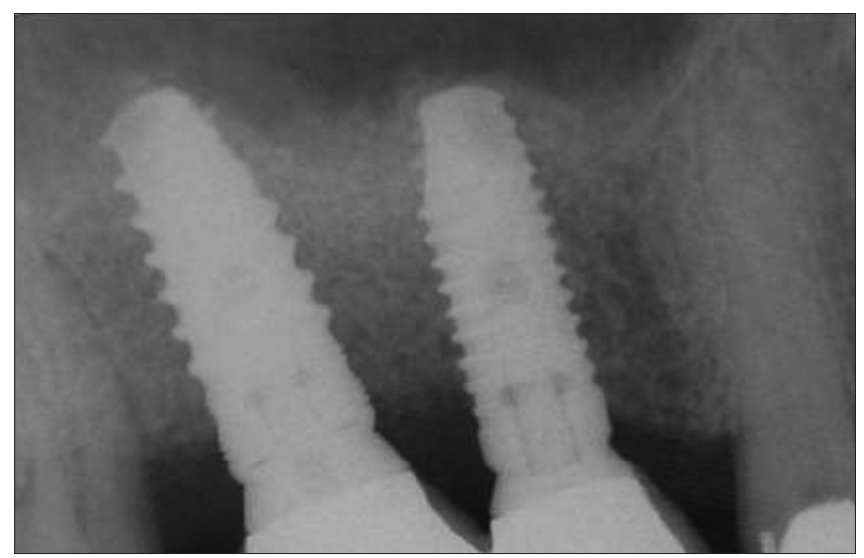

Figure 4: Periapical radiograph taken at same appointment as the fit of the cement-retained porcelain-bonded crowns. 7.5 months postsurgery

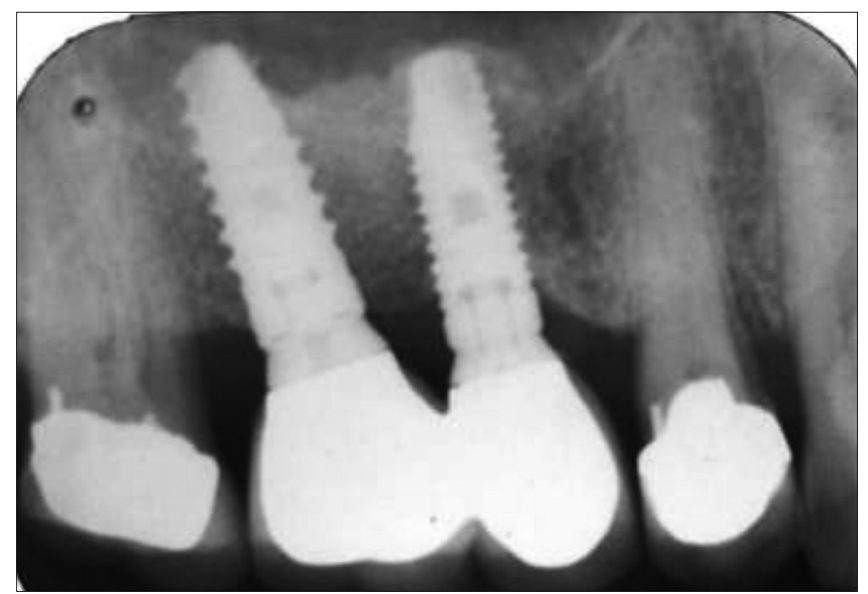

Figure 6: Periapical radiograph taken at 19.5 months postsurgery

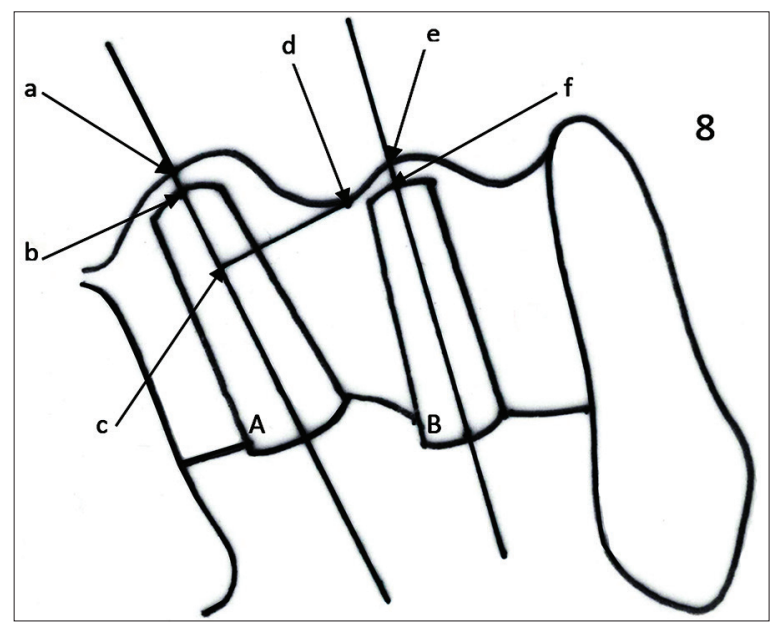

Figure 8: Schematic of the measurements taken from each radiograph: Graft height above implant A, distance ab, Graft height above implant B, distance ef, Graft height at lowest point between implants $\mathrm{A}$ and $\mathrm{B}$ (position $\mathrm{d}$ ), at a tangent to implant A (position c) reported, ${ }^{[20]}$ specific bone-implant-contact sites and graft region above the original sinus floor-were investigated for their pixel density; that recorded pixel-density inferring the relative bone-density values at those sites [Figure 7]. Additionally, the mid-points of the graft opposing the original sinus floor and the new highest point of the augmented sinus floor. The average of five recordings of the bone density at each site under scrutiny was given as a percentage of its control.

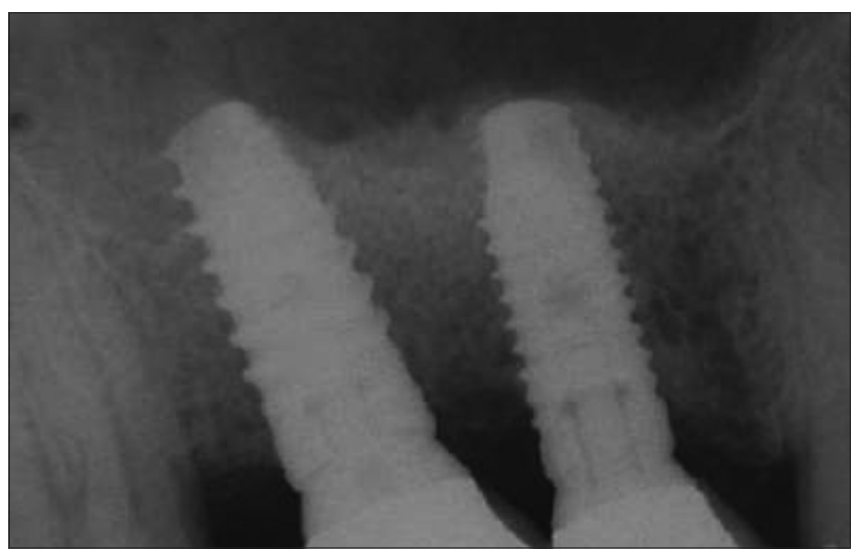

Figure 5: Periapical radiograph taken at 13.5 months postsurgery

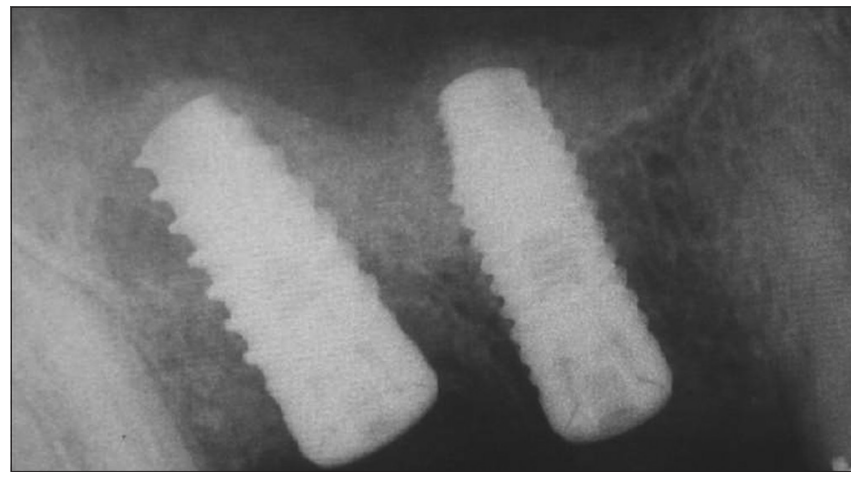

Figure 7: Radiograph displaying the actual areas at which the pixeldensity was measured on each periapical radiograph. The numbers correlate to the rows on the tables

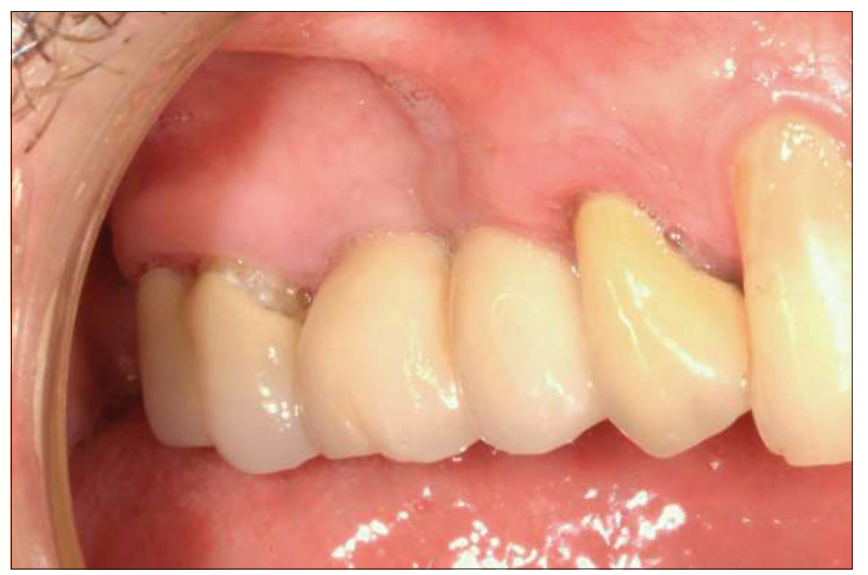

Figure 9: Clinical situation 12 months postloading 
Using the known actual length of the inserted implants, the following measurements were determined on each individual implant [Figure 8]:

- Graft height above implant A

- Graft height above implant B

- Graft height at lowest point between implants A and $\mathrm{B}$, at a tangent to implant $\mathrm{A}$.

To evaluate the changes in graft height, these measurements were repeated on each follow-up radiograph [Figure 8]. These measurements were performed by a single operator.

\section{RESULTS}

Over a period of 19.5 months from base-line (day of surgery) there was progressive loss of sinus floor height over the apex of each implant, whilst the sinus floor height between the implants showed a gain over that same period. The overall pixel density of the sinus graft increased from baseline to 6 months, however, with 6 months of loading that pixel density decreased progressively to 19.5 months [Tables 1-5].

\section{DISCUSSION}

Where implants are planned for placement into pneumatised sinuses, inadequate depths of implant

\begin{tabular}{|c|c|c|c|c|c|c|c|}
\hline \multirow[t]{2}{*}{ Site } & \multicolumn{7}{|c|}{ Pixel density of the randomized sites } \\
\hline & 1 & 2 & 3 & 4 & 5 & $\begin{array}{l}\text { Average } \\
\text { value }\end{array}$ & $\begin{array}{c}\text { Percentage value } \\
\text { of control (150) }\end{array}$ \\
\hline 1 & 95 & 96 & 97 & 97 & 96 & 96.2 & 64.1 \\
\hline 2 & 104 & 105 & 107 & 104 & 108 & 105.6 & 70.4 \\
\hline 3 & 105 & 103 & 105 & 103 & 106 & 104.4 & 69.6 \\
\hline 4 & 83 & 83 & 80 & 83 & 83 & 82.4 & 54.9 \\
\hline 5 & 82 & 82 & 78 & 81 & 81 & 80.8 & 53.9 \\
\hline 6 & 58 & 57 & 59 & 60 & 58 & 58.4 & 38.9 \\
\hline 7 & 76 & 77 & 76 & 78 & 80 & 77.4 & 51.6 \\
\hline
\end{tabular}

\begin{tabular}{|c|c|c|c|c|c|c|c|}
\hline \multirow[t]{2}{*}{ Site } & \multicolumn{7}{|c|}{ Pixel density at each randomized site } \\
\hline & 1 & 2 & 3 & 4 & 5 & $\begin{array}{l}\text { Average } \\
\text { value }\end{array}$ & $\begin{array}{c}\text { Percentage value } \\
\text { of control (155) }\end{array}$ \\
\hline 1 & 102 & 102 & 102 & 102 & 102 & 102 & 65.8 \\
\hline 2 & 109 & 109 & 111 & 109 & 112 & 110 & 71 \\
\hline 3 & 105 & 105 & 106 & 105 & 105 & 105.2 & 67.9 \\
\hline 4 & 106 & 104 & 106 & 104 & 104 & 104.8 & 67.6 \\
\hline 5 & 99 & 98 & 99 & 100 & 97 & 98.6 & 63.6 \\
\hline 6 & 88 & 90 & 91 & 90 & 90 & 89.8 & 57.9 \\
\hline 7 & 93 & 93 & 92 & 91 & 92 & 92.2 & 59.5 \\
\hline
\end{tabular}

beds are often augmented. Where multiple implants are planned, lateral open-window (LW) surgical sites facilitate the placing of a large volume of sinus graft material, dependant on the achievement of high primary stability; implants will be placed immediately or at a later date. If a single implant is to be placed into a deficient bone depth site, the transcrestal sinus graft technique is often employed (the BAOSFE), the implant being placed immediately or at a later date. The novel method investigated here was the use of the BAOSFE technique at adjacent osteotomies, thus allowing the introduction of a large volume of graft material similar to the lateral window technique but in a less invasive manner, and place multiple implants immediately.

\begin{tabular}{llcccccc}
$\begin{array}{l}\text { Table 3: Evaluation of radiograph, Figure } \mathbf{5} \text { taken } \mathbf{6} \\
\text { months postloading, } \\
\text { (3.5 }\end{array}$ months from base-line \\
\hline Site & \multicolumn{6}{c}{ Pixel density at each randomized site } \\
\cline { 2 - 8 } & $\mathbf{1}$ & $\mathbf{2}$ & $\mathbf{3}$ & $\mathbf{4}$ & $\mathbf{5}$ & $\begin{array}{c}\text { Average } \\
\text { value }\end{array}$ & $\begin{array}{c}\text { Percentage value } \\
\text { of control (150) }\end{array}$ \\
\hline 1 & 95 & 96 & 97 & 06 & 97 & 96.2 & 64 \\
2 & 95 & 96 & 95 & 94 & 95 & 95 & 63.3 \\
3 & 90 & 93 & 91 & 90 & 90 & 91 & 61 \\
4 & 94 & 94 & 94 & 94 & 94 & 94 & 63 \\
5 & 83 & 85 & 82 & 82 & 82 & 82.8 & 55.2 \\
6 & 72 & 75 & 73 & 75 & 78 & 74.6 & 49.7 \\
7 & 83 & 84 & 82 & 83 & 82 & 82.8 & 55.2 \\
\hline
\end{tabular}

\begin{tabular}{|c|c|c|c|c|c|c|c|}
\hline \multirow[t]{2}{*}{ Site } & \multicolumn{7}{|c|}{ Pixel density at each randomized site } \\
\hline & 1 & 2 & 3 & 4 & 5 & $\begin{array}{c}\text { Average } \\
\text { value }\end{array}$ & $\begin{array}{l}\text { Percentage } \\
\text { value of } \\
\text { control (240) }\end{array}$ \\
\hline 1 & 127.23 & 122.59 & 124.47 & 125.78 & 125.81 & 125.18 & 52.2 \\
\hline 2 & 126.91 & 127.27 & 125.62 & 127.78 & 124.43 & 126.40 & 52.7 \\
\hline 3 & 126.93 & 137.89 & 133.54 & 143.70 & 145.86 & 137.58 & 57.3 \\
\hline 4 & 137.10 & 135.51 & 137.34 & 139.58 & 140.91 & 138.09 & 57.5 \\
\hline 5 & 155.87 & 153.53 & 152.97 & 155.14 & 155.38 & 154.58 & 64.4 \\
\hline 6 & 128.13 & 127.62 & 128.07 & $127 / 01$ & 128.58 & 127.88 & 53.3 \\
\hline 7 & 123.23 & 122.61 & 124.66 & 124.17 & 123.07 & 123.55 & 51.5 \\
\hline
\end{tabular}

\begin{tabular}{lcccc}
\multicolumn{4}{l}{ Table 5: Pixel density value change with time, months } \\
\hline Site & $\begin{array}{c}\text { Base-line } \\
\%\end{array}$ & $\begin{array}{c}\mathbf{6} \text { months } \\
\text { \% }\end{array}$ & $\begin{array}{c}\mathbf{1 3 . 5} \text { months } \\
\text { \% }\end{array}$ & $\begin{array}{c}\mathbf{1 9 . 5} \text { months } \\
\text { \% }\end{array}$ \\
\hline 1 & 64.1 & 65.8 & 64 & 52.2 \\
2 & 70.4 & 71 & 63.3 & 52.7 \\
3 & 69.6 & 67.9 & 61 & 57.3 \\
4 & 54.9 & 67.6 & 63 & 57.5 \\
5 & 53.9 & 63.6 & 55.2 & 64.4 \\
6 & 38.9 & 57.9 & 49.7 & 53.3 \\
7 & 51.6 & 59.5 & 55.2 & 51.5 \\
\hline
\end{tabular}


McCrea: Coalescence of separate transcrestal sinus grafts

\begin{tabular}{|c|c|c|c|c|}
\hline Time scale, months & 0 , base-line & 6 months & 13.5 months & 19.5 months \\
\hline Graft height above implant $A$ & 1.17 & 0.79 & 0 & -1.56 \\
\hline Graft height above implant B & 0.73 & 0.61 & 0.32 & 0.23 \\
\hline $\begin{array}{l}\text { Graft height at lowest point } \\
\text { between implants } A \text { and } B \text { and } \\
\text { at a tangent to implant } A\end{array}$ & 6.99 & 7.87 & 8.33 & 8.67 \\
\hline
\end{tabular}

The progressive loss of graft material from around the apex of the implants is the expectation when either the lateral-window technique or the BAOSFE are used. The preliminary report of this coalescence method produced the same result as the LW and BAOSFE methods - Table 6. The explanation of this phenomena is already given: During this early period graft material can be resorbed by basic multicellular units and becomes surrounded by de novo bone which is then remodelled by secondary bone formation as a result of loading.

The progressive loss of the inter-implant sinus bone graft is also reported for both the LW and BAOSFE techniques. However, this novel coalescence method has shown a progressive increase in the inter-implant sinus graft region, thus, inferring a positive bony regeneration and remodelling at the region-Table 6 .

\section{CONCLUSION}

The maintenance of bone height in the inter-implant region of a sinus graft will be conducive to the long term stability of the implants adjacent to the region. The results of this preliminary investigation indicate that the carrying out of a large-scale study is warranted to confirm the efficacy of this novel technique.

\section{REFERENCES}

1. Pietrokovski J, Starinsky R, Arensburg B, Kaffe I. Morphologic characteristics of bony edentulous jaws. J Prosthodont 2007;16:141-7.

2. Van der Weijden F, Dell'Acqua F, Slot DE. Alveolar bone dimensional changes of post-extraction sockets in humans: A systematic review. J Clin Periodontol 2009;36:1048-58.

3. Chanavaz M. Maxillary sinus: Anatomy, physiology, surgery, and bone grafting related to implantology - Eleven years of surgical experience (1979-1990). J Oral Implantol 1990;16:199-209.

4. Palma VC, Magro-Filho O, de Oliveria JA, Lundgren S, Salata LA, Sennerby L. Bone reformation and implant integration following maxillary sinus membrane elevation: An experimental study in primates. Clin Implant Dent Relat Res 2006;8:11-24.

5. Wheeler SL, Holmes RE, Calhoun CJ. Six-year clinical and histologic study of sinus-lift grafts. Int J Oral Maxillofac Implants 1996;11:26-34.
6. McCrea SJ. Trans-socket elevation/fracture/perforation of the sinus floor through the 'infected' maxillary tooth socket to facilitate bicortical fixation of dental implants. Clin Adv Periodontics 2012;2:80-7.

7. Pjetursson BE, Tan WC, Zwahlen M, Lang NP. A systematic review of the success of sinus floor elevation and survival of implants inserted in combination with sinus floor elevation. J Clin Periodontol 2008;35:216-40.

8. Esposito M, Grusovin MG, Rees J, Karasoulos D, Felice P, Alissa R, et al. Interventions for replacing missing teeth: Augmentation procedures of the maxillary sinus. Cochrane Database Syst Rev 2014;5:CD008397.

9. Boyne PJ, James RA. Grafting of the maxillary sinus floor with autogenous marrow and bone. J Oral Surg 1980;38:613-6.

10. Tatum H Jr. Maxillary and sinus implant reconstructions. Dent Clin North Am 1986;30:207-29.

11. Summers RB. A new concept in maxillary implant surgery: The osteotome technique. Compendium 1994;15:152, 154-6, 158, 162.

12. Summers RB. The osteotome technique: Part 3 - Less invasive methods of elevating the sinus floor. Compendium 1994;15:698, 700, 702-4, 710 .

13. Aghaloo TL, Moy PK. Which hard tissue augmentation techniques are the most successful in furnishing bony support for implant placement? Int J Oral Maxillofac Implants 2007;22 Suppl: 49-70.

14. Del Fabbro M, Rosano G, Taschieri S. Implant survival rates after maxillary sinus augmentation. Eur J Oral Sci 2008;116:497-506.

15. Hatano N, Shimizu Y, Ooya K. A clinical long-term radiographic evaluation of graft height changes after maxillary sinus floor augmentation with a 2:1 autogenous bone/xenograft mixture and simultaneous placement of dental implants. Clin Oral Implants Res 2004;15:339-45.

16. Trombelli L, Franceschetti G, Rizzi A, Minenna P, Minenna L, Farina R. Minimally invasive transcrestal sinus floor elevation with graft biomaterials. A randomized clinical trial. Clin Oral Implants Res 2012;23:424-32.

17. Covani U, Cornelini R, Barone A. Bucco-lingual bone remodeling around implants placed into immediate extraction sockets: A case series. J Periodontol 2003;74:268-73.

18. Araújo MG, Lindhe J. Dimensional ridge alterations following tooth extraction. An experimental study in the dog. J Clin Periodontol 2005;32:212-8.

19. Engelke W, Deckwer I. Endoscopically controlled sinus floor augmentation. A preliminary report. Clin Oral Implants Res 1997;8:527-31.

20. McCrea SJ, Makdissi J. A comparison of natural bone regeneration with that produced by the xenograft Bio-Oss in the management of an unusual case of adjacent dentigerous cysts. Oral Surg 2010;2:136-43.

\begin{tabular}{|l|l|}
\hline \multicolumn{2}{|c|}{ Access this article online } \\
\hline Quick Response Code: & Website: \\
\hline
\end{tabular}

